\title{
DETERMINANTS OF ORCHID SPECIES DIVERSITY IN LATIN AMERICA
}

\author{
Zuzana Štípková ${ }^{1,2}$, Iva Traxmandlová ${ }^{1} \&$ Pavel Kindlmann ${ }^{1-3}$ \\ ${ }^{1}$ Global Change Research Institute, Academy of Sciences of the Czech Republic, Prokišova 356/7, \\ České Budějovice, 37001, Czech Republic \\ ${ }^{2}$ Institute for Environmental Studies, Faculty of Science, Charles University, Benátská 2, Prague, 12801, \\ Czech Republic \\ ${ }^{3}$ Author for correspondence: pavel.kindlmann@centrum.cz
}

\begin{abstract}
Area and latitude are thought to be the most important determinants of species richness. The relative importance of these two factors was recently tested, using data on orchid species diversity in various countries in the world and it was found that size of the country (or of the protected areas within the country) is a better determinant of species diversity in orchids than latitude. On the other hand, literature data indicate that in many groups species richness is also heavily dependent on habitat diversity as expressed by the range of altitudes in the region considered. Here we analyze the species richness data for various countries in Latin America, using the above-mentioned altitudinal amplitude as a proxy. Habitat diversity played a role in tropical, but not in temperate countries. The reason may indicate that in the temperate countries only few orchid species grow in higher elevations, so an increase of altitudinal range of habitats there does not entail a corresponding increase of species richness there. Thus, especially in the tropics, efforts should be directed to preservation of protected areas in all altitudes, rather than to increase of existing reserve size only in areas that are not attractive for human development.
\end{abstract}

KEY WORDS: altitude, habitat diversity, species-area relationship

Introduction. Questions concerning species diversity have attracted ecologists for over a century. Recently this issue became even more important, because the diversity of life on Earth is in rapid decline (Dirzo \& Raven 2003, Possingham \& Wilson 2005). Therefore, one of the most pressing tasks facing the global conservation community is trying to understand the main factors determining diversity of species (Possingham \& Wilson 2005) and identifying important areas for their conservation (Tsiftsis et al. 2011), as this is crucial for their survival. This especially holds for threatened groups such as orchids (Efimov 2011, Feldman \& Prat 2011).

For any group of organisms, the most important determinants of species richness are thought to be area, latitude and energy availability (Schödelbauerová et al. 2009). Specifically, the increase in species richness with decreasing latitude from the poles to the tropics (Pianka 1966, Rohde 1992, Willig et al. 2003, Hillebrand 2004) was well documented and so was the increase in species richness with increasing area (Arrhenius 1921, Gleason 1922, Williamson 1988, Rosenzweig 1995). More recently, the amount of energy available (i.e. that which can be converted into biomass) for net primary productivity has been revealed to be also an important determinant of species richness (Wright 1983, Wylie \& Currie 1993a, 1993b, Pelkey et al. 2000, Evans et al. 2005, Storch et al. 2005).

The relative importance of these factors was recently tested, using data on orchid species diversity in various countries in the world (Schödelbauerová et al. 2009) and it was found that size of the region considered is a better determinant of species diversity in orchids than its latitude.

However, the habitat heterogeneity hypothesis states that also an increase in habitat heterogeneity leads to an increase in species diversity (Cramer $\&$ Willig 2005). The effect of habitat diversity on species diversity was empirically supported by the 
TABLE 1. Sources for the numbers of orchid species countries from Central and South America.

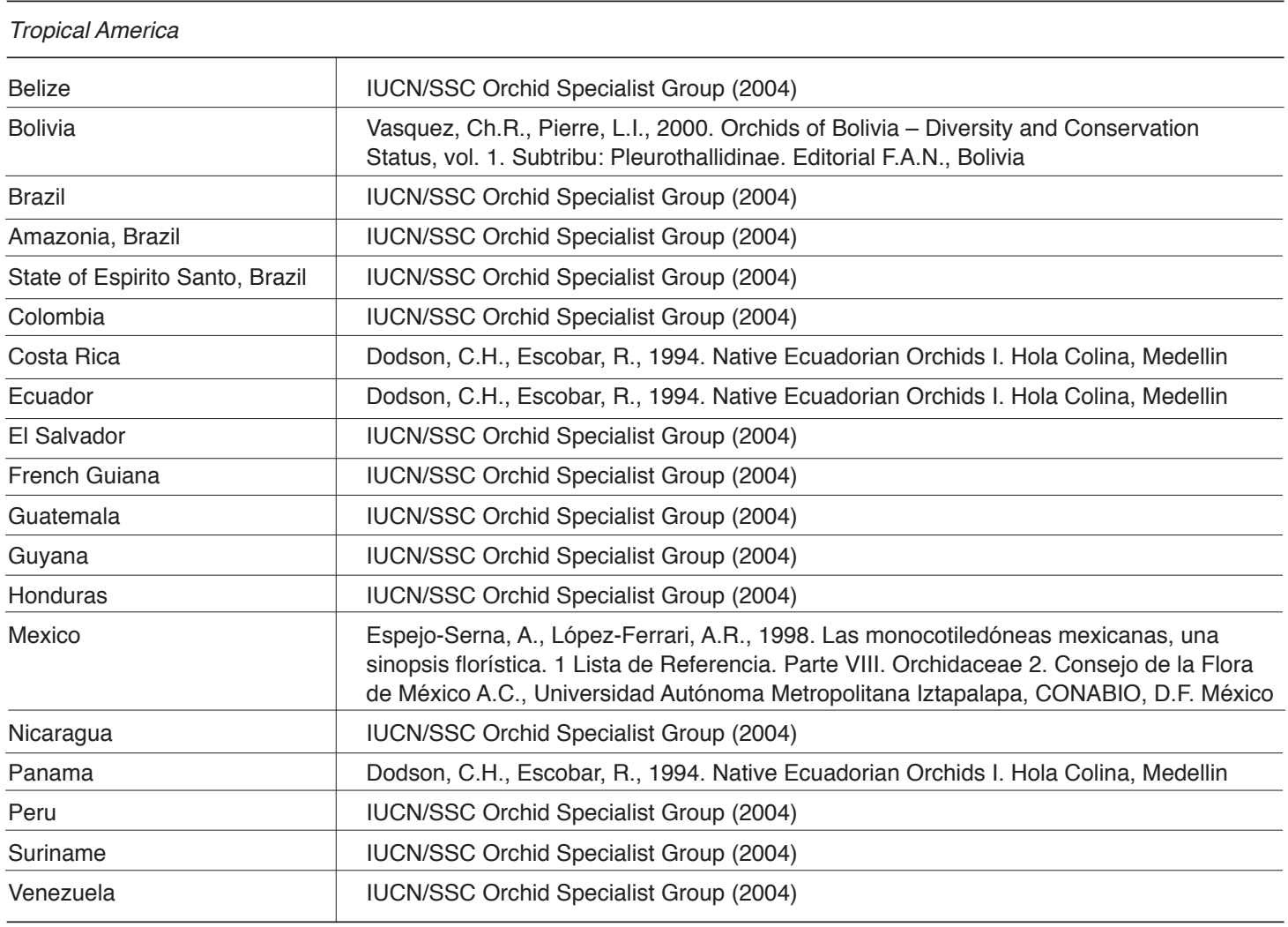

Temperate America

\begin{tabular}{l|l}
\hline Argentina & IUCN/SSC Orchid Specialist Group (2004) \\
\hline Chile & IUCN/SSC Orchid Specialist Group (2004) \\
\hline Paraguay & IUCN/SSC Orchid Specialist Group (2004) \\
\hline Uruguay & IUCN/SSC Orchid Specialist Group (2004) \\
\hline
\end{tabular}

data on orchids in the Caribbean islands (Ackerman et al. 2007), but habitat heterogeneity has never been considered in the context of orchids growing on the mainland - e.g., various countries in a continent. The result obtained for islands (that increase in habitat heterogeneity leads to an increase in species diversity) cannot be automatically transferred to the case of a set of patches on the mainland (like various countries in a continent). The reason is that while islands are surrounded by a completely inhospitable area for orchids (sea), the area between individual patches on the mainland is covered by various types of habitat (usually called "matrix"), some of which ("hospitable patches") can be inhabited by the taxonomic group in question (orchids in this case). Therefore, these "hospitable patches" may act as stepping stones for migration of species between the patches studied. This also holds for passively migrating groups, like orchids. Their seeds originating from patch A may be blown by wind, germinate on these stepping stones and their descendant seeds may finally reach some other patch B. If the distance between patches A and $\mathrm{B}$ is large and therefore the likelihood that a seed originating from patch A will reach directly patch $\mathrm{B}$, then the presence of the stepping stone increases the probability that species originating from patch $\mathrm{A}$ finally colonizes patch B via descendants of the seeds produced in patch $\mathrm{A}$. 
TABLE 2. Models tested, their parameters, and the corresponding t-, p- and $\mathrm{R}^{2}$-values.

\begin{tabular}{|c|c|c|c|c|c|}
\hline Model & Coefficient & Value & $\mathbf{t}$ & p & $\mathbf{R}^{2}$ \\
\hline$S=a^{\star} A l t+b^{\star} A+c$ & $\begin{array}{l}a \\
b \\
c\end{array}$ & $\begin{array}{c}0.32 \\
0.0001 \\
-198.13\end{array}$ & $\begin{array}{c}4.14 \\
1.97 \\
-0.62\end{array}$ & $\begin{array}{c}<0.05 \\
0.07 \\
0.55\end{array}$ & 0.58 \\
\hline$S=a^{*} A l t+b^{*} \ln A+c$ & $\begin{array}{l}a \\
b \\
c\end{array}$ & $\begin{array}{c}0.28 \\
112.3 \\
-1300.6\end{array}$ & $\begin{array}{c}2.89 \\
1.11 \\
-1.14\end{array}$ & $\begin{array}{c}<0.05 \\
0.28 \\
0.27\end{array}$ & 0.52 \\
\hline $\ln S=a^{\star} A l t+b^{\star} \ln A+c$ & $\begin{array}{l}a \\
b \\
c\end{array}$ & $\begin{array}{c}0.0003 \\
0.11 \\
4.41\end{array}$ & $\begin{array}{l}4.15 \\
1.64 \\
5.84\end{array}$ & $\begin{array}{c}<0.05 \\
0.12 \\
<0.05\end{array}$ & 0.69 \\
\hline
\end{tabular}

Here we show our results on the combined effect of area and habitat diversity on orchid species diversity in various countries, using data from Central and South America. Our results therefore provide a comparison of the results already obtained in islands with those for mainland.

Methods. The numbers of orchid species (S) for 23 countries or parts thereof from Central and South America and their areas were obtained from published articles and floras (Table 1). These countries were divided into temperate (Argentina, Chile, Paraguay and Uruguay) and tropical ones (the remaining 19 countries). Area (A) and habitat diversity, estimated by the altitudinal difference between the highest and lowest point in the country (Alt), were then obtained from web sites of these countries or using Google Earth.

We used both univariate (power function for $\mathrm{S}=$ $\mathrm{f}(\mathrm{A})$ and exponential for $\mathrm{S}=\mathrm{f}(\mathrm{Alt})$ ) and 3 different linear bivariate models (see Table 2 for their list). Only univariate models were used for temperate countries, as for only 4 countries there was no point in fitting the data by bivariate models.

Results. We analysed 19 tropical countries and areas (parts of a country) and 4 temperate countries in Latin America. The species-area relationships for tropical and temperate countries are shown in Fig. 1. Area of the country explained $39 \%$ of the variability in temperate countries and $36 \%$ of the variability in tropical countries.

The dependence of the number of orchid species on habitat diversity approximated as the difference between the altitude of the highest and that of the lowest point in the country is shown in Fig. 2. For tropical countries, habitat diversity was even a better predictor of the number of orchid species than area, as it explained $64 \%$ of the variability. In the temperate countries, habitat diversity explained only $5 \%$ of the total variability.

Table 2 summarizes the models tested, their parameters, and the corresponding $\mathrm{t}-, \mathrm{p}-$ and $\mathrm{R}^{2}$ values. The coefficient $a$ for habitat diversity, approximated as the difference between the altitude of the highest and that of the lowest point in the country was always significantly different from zero, as indicated by the p-value, so habitat heterogeneity should never be neglected. The $\mathrm{R}^{2}$-values indicating the percentage of explained variability by the model show that the best model is the third one, i.e., $\ln \mathrm{S}=$ $a^{*}$ Alt $+b^{*} \ln A+c$.

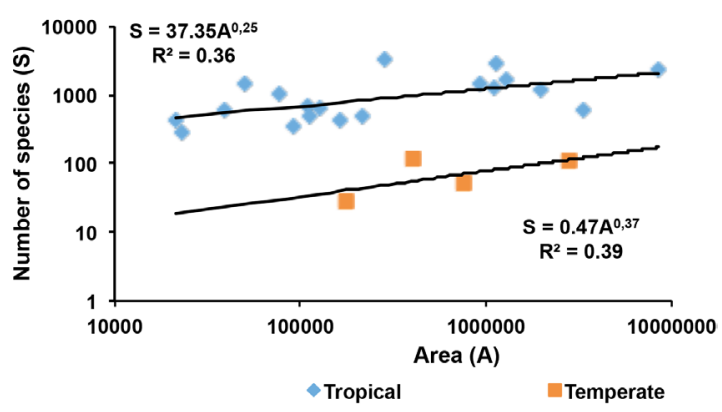

FiguRE 1. The species-area relationship, for temperate and tropical countries separately. 


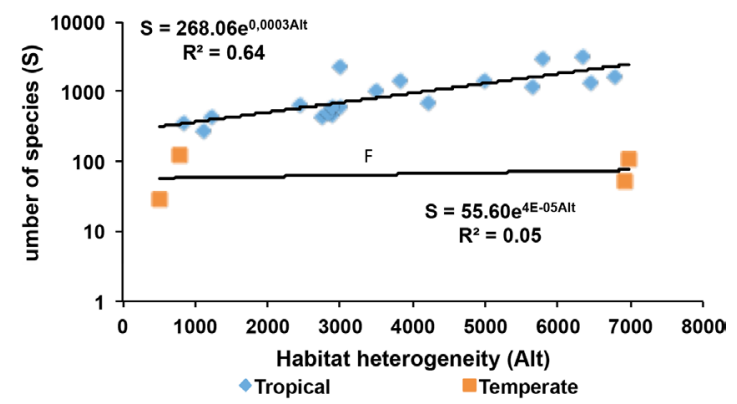

FIGURE 2.The dependence of the number of species on the altitudinal difference between the highest and lowest point in the country (Alt). Alt represents an estimate of habitat diversity in the country..

Discussion. The model $\ln \mathrm{S}=\mathrm{a}^{*} \mathrm{Alt}+\mathrm{b} * \ln \mathrm{A}+\mathrm{c}$ best fitted the data on orchid species richness, which only reconfirms the well known fact that a power function is the best one for fitting the species-area relationships. Not surprisingly, the effect of latitude is expressed by lower intercept in Fig. 1 for temperate countries. The importance of the slightly larger exponent for temperate countries cannot be overestimated because of the low number of these countries.

Habitat diversity, as expressed by the difference in altitudes between the highest peak and lowest point in the country considered, played a role in tropical, but not in temperate countries (Fig. 2). The reason may be that in temperate countries only few orchid species grow in higher elevations, so an increase of altitudinal range of habitats there does not entail a corresponding increase of species richness.

Both figures and the table indicate that the effect of habitat diversity was stronger than that of country size in tropical countries. Thus, especially in the tropics, efforts should be directed to preservation of protected areas in all altitudes, rather than to increase of existing reserve size only in areas that are not attractive for human development.

Altitudinal amplitude is used as a proxy for habitat here. Of course, with increasing altitude comes slightly increasing area compared to the basal area of the country. This could be a confounding factor in our study. However, first - the increase of area caused by habitat heterogeneity is relatively small (altitudinal differences per kilometre are usually in the range of several hundreds of meters at most). Second - even if we accept there is a positive correlation between area and habitat diversity per unit basal area, then this increase just becomes one of the components of the effect of habitat diversity. This is not to say that this effect should not be completely ignored, however. Our results show a strong correlation with habitat diversity, which would suggest potentially narrow habitat ranges of species. This may have some implications particularly in the light of climate change: if temperature will increase, the species will most likely move upwards and if there is no space there (top of the mountain), the only chance for them to survive will be to move to another patch. Even if there will be space in higher elevations, the basic topological considerations imply that its amount may be lower.

The potentially narrow habitat ranges of species may also have important implications in protected area management: maintenance of present locations of species may then become very important, as other locations may be unsuitable because of this narrow habitat range.

ACKNOWLEDGEMENTS. This research was supported by the grant No. 14-36098G of the GA CR to PK and ZS and by the MSMT within the National Sustainability Program I (NPU I), grant number LO1415 to IT.

\section{Literature Cited}

Ackerman, J.D., Trejo-Torres, J.C. \& Crespo-Chuy, Y. (2007). Orchids of the West Indies: predictability of Diversity and endemism. Journal of Biogeography, 34, 779-786.

Arrhenius, O. (1921). Species and area. Journal of Ecology, 9, 95-99.

Cramer, M.J. \& Willig, M.R. (2005). Habitat heterogeneity, species diversity and null models. Oikos, 108, 209-218.

Dirzo, R. \& Raven, P.H. (2003). Global state of biodiversity and loss. Annual Review of Environmental Research, 28, 137-167.

Efimov, P.G. (2011). Revealing the decline and expansion of orchids of NW European Russia. European Journal of Environmental Sciences, 1(2), 7-17.

Evans, K.L., Greenwood, J.J.D. \& Gaston, K.J. (2005). The roles of extinction colonization in generating speciesenergy relationships. Journal of Animal Ecology, 74, 498-507.

Feldman, D. \& Prat, D. (2011). Conservation recommendations from a large survey of French orchids. European Journal of Environmental Sciences, 1(2), 8-27. 
Gleason, H.A. (1922). On the relation between species and area. Ecology, 3, 158-162.

Hillebrand, H. (2004). On the generality of the latitudinal diversity gradient. American Naturalist, 163, 192-211.

Pelkey, N.W., Stoner, C.J. \& Caro, T.M. (2000). Vegetation in Tanzania: assessing long term trends and effects of protection using satellite imagery. Biological Conservation, 94, 297-309.

Pianka, E.R. (1966). Latitudinal gradients in species diversity: a review of concepts. American Naturalist, 100, 33-46.

Possingham, H. P. \& Wilson, K.A. (2005). Turning up the heat on hotspots. Nature, 436, 919-920.

Rohde, K. (1992). Latitudinal gradients in species diversity: the search for the primary cause. Oikos, 65, 514-527.

Rosenzweig, M.L. (1995). Species Diversity in Space and Time. Cambridge University Press, Cambridge.

Schödelbauerová, I., Roberts, D.L. \& Kindlmann, P. (2009). Size of protected areas is the main determinant of species diversity in orchids. Biological Conservation, 142, 2329-2334.

Storch, D., Evans, K.L. \& Gaston, K.J. (2005). The speciesarea-energy relationship. Ecology Letters, 8, 487-492.
Tsiftsis, S., Tsiripidis, I. \& Trigas, R. (2011). Identifying important areas for orchid conservation in Crete. European Journal of Environmental Sciences, 1(2), 28-37.

Williamson, M.H. (1988). Relationship of species number to area, distance and other variables. In: A.A. Myers \& P.S. Giller (eds.), Analytical Biogeography (pp. 91115). London: Chapman and Hall.

Willig, M.R., Kaufman, D.M. \& Stevens, R.D. (2003). Latitudinal gradients in biodiversity: pattern, process, scale, and synthesis. Annual Review or Ecology and Systematics, 34, 273-309.

Wright, D.H. (1983). Species-energy theory: an extension of species-area theory. Oikos, 41, 496-506.

Wylie, J.L. \& Currie, D.J. (1993a). Species-energy theory and patterns of species richness: I. Patterns of bird, angiosperm, and mammal species richness on islands. Biological Conservation, 63, 137-144.

Wylie, J.L. \& Currie, D.J. (1993b). Species-energy theory and patterns of species richness: II. Predicting mammal species richness on isolated nature reserves. Biological Conservation, 63, 145-148. 
LANKESTERIANA • V SCIENTIFIC CONFERENCE ON ANDEAN ORCHIDS 